\title{
CORRIGENDUM: Epidemiologic and economic consequences of the global epidemics of obesity and diabetes
}

D Yach, D Stuckler \& K D Brownell

Nat. Med. 12, 62-66; 2006; published online 5 January 2006; corrected 24 February 2006

In the version of this article initially published, some information about sources was omitted. The citation of the data source for Table $\mathbf{1}$ should have included a reference to the World Health Organization SuRF 2 Report for the country estimates and the World Health Organization Global InfoBase for Global/Income group estimates. Figures 1 and 2 should have included a reference to Wild et al. (Diabetes Care 27, 1047-1053; 2004). This error has been corrected in the PDF version of the article.

CORRIGENDUM: NK cells promote islet allograft tolerance via a perforindependent mechanism

J N Beilke, N R Kuhl, L Van Kaer \& R G Gill

Nat. Med. 11, 1059-1065 (2005); published online 11 September 2005; corrected 24 February 2006

In the version of this article initially published, the authors inadvertently misquoted a study as evidence that mouse NKT cells can express CD154 (ref. 29). Rather, the cited study concerned CD40-CD40L interactions in human NK cells. By misquoting this study, the authors also omitted an appropriate reference regarding prior evidence of CD40-CD40L interactions by murine NKT cells (Kitamura, H. et al., J. Exp. Med. 189, 1121; 1999). These errors have been corrected in the PDF version online. 